\title{
태풍피해자료를 이용한 태풍위험지수 개발 Development of a Typhoon Risk Index (TRI) Based on Records of Typhoon Damage
}

\author{
김연수* . 이보림** . 김태균*** \\ Kim, Yonsoo*, Lee, Borim**, and Kim, Taegyun***
}

\begin{abstract}
Typhoon cause damage through simultaneous flooding, strong winds, and storms; they have been one of the most damaging disasters of the last decade. In this study, we develop a typhoon risk index (TRI) based on records of typhoon damage that occurred in 229 municipalities across South Korea since 1994. The TRI employs a pressure-state-response (PSR) framework system. For the pressure index (PI), we use ten indicators that represent hydro-meteorological, regional, and socio-economic characteristics. The state index (SI) includes three indicators related to typhoons and the response index (RI) comprises six indicators including financial status and disaster mitigation-related projects and facilities. The weighting of each indicator for the TRI was calculated using an entropy method. The PIs are higher in the Seoul metropolitan and southern coast areas of the Korean peninsula. The SIs are higher for the southern and eastern coastal areas. It is not easy to determine a regional trend for the RIs. The TRI is higher for the southern and eastern coasts and the Jirisan and Deogyusan areas. These regions are consistent with the areas where typhoons have frequently caused damage. The TRI developed in this research will contribute to decision-making about the priority of disaster prevention projects to mitigate typhoon damage.
\end{abstract}

Key words : Typhoon Damage Index, PSR Structure System, Entropy Method

\section{요 지}

태풍피해는 호우로 인한 홍수, 강풍, 풍랑 등 3 가지 피해가 동시에 발생하는 재해로, 지난 10 년간 피해액 기준으로 가장 큰 피해를 일으켰다. 본 연구에서는 전국 229개 시군구를 대상으로 1994년 이후 발생한 태풍피해자료를 이용하여 태풍위험지수 (TRI)를 개발하였다. 태풍위험지수는 PSR 구조체계를 이용하여 시군구별로 개발하였다. 압력지수(PI)는 수문기상, 지역특성, 사회경제적 지표 등 10 개 지표를, 상태지수(SI)는 피해 관련 3 개 지표를, 대책지수(RI)는 재정상태, 방재관련 사업, 시설 등 6 개 지표를 이용하였다. 지수산정을 위한 각 지표의 가중치는 엔트로피 방법을 이용하였다. 압력지수는 수도권과 남해안 지역이 높게 나타났고, 상태지수는 남해안과 동해안 지역이 높게 나타났으나, 대책지수는 지역적 경향성을 찾기 어려웠다. 태풍위험지수는 남해안과 동해안 및 지리산, 덕유산 인근 지역이 높게 나타났으며, 이는 태풍피해 다발지역과 일치하는 것을 알 수 있다. 개발된 태풍위험지수는 태풍에 위한 피해를 감소하기 위한 대비와 방재 관련 사업의 우선순위를 결정하는데 이용될 수 있을 것이다.

핵심용어 : 태풍위험지수, PSR 구조체계, 엔트로피 가중치

*정회원, (주)LIG시스템 위험관리연구소 책임연구원(E-mail: civil.engineer@hanmail.net)

Member, Senior Researcher, Risk Management Institute, LIG System Co., Ltd

**(주)강산 사원(E-mail: hoyoungqr@naver.com)

Staff, Kangsan Co., Ltd

***교신저자, 정회원, 경남과학기술대학교 조경학과 교수(Tel: +82-55-751-3306, Fax: +82-55-751-3309, E-mail: tgkim@gntech.ac.kr)

Corresponding Author, Member, Professor. Department of Landscape Architecture 


\section{1. 서 론}

2017년 기준으로 과거 10년 동안 자연재해로 인한 연평균 피해액은 3,486 억 원, 연평균 복구비는 2 배에 근접하는 7,281 억 원에 달하며, 인명피해는 연평균 15.2 명 정도로 이른다(MOIS, 2017). 과거 10년간의 자연재해 원인별 피해 액을 살펴보면 태풍, 호우에 의한 피해가 전체의 $88.4 \%$ 로 대부분을 차지하고 대설, 지진, 풍랑 및 강풍 순으로 피해가 발생하였다.

홍수, 가뭄, 급경사지의 안전 등 자연재해에 효율적으로 대비하기 위한 연구의 일환으로 자연재해에 대한 발생 위험 을 나타내는 위험지수, 취약성 지수 등 다양한 지수가 개발되 고 있다. MOCT (2001)은 홍수피해잠재능(Potential Flood Damage, PFD)를 도입하여 치수안전도 설정을 위한 지표로 이용하였고, Kim and Kim (2003)은 PFD를 개선한 수정 $\mathrm{PFD}$ 를 제시하였고, KRIHS (2005)는 홍수피해의 잠재적 위험성을 나타내는 홍수피해지표를 시군구별로 산정하였 다. Chae et al. (2009)은 급경사지 재해취약성 평가를 위한 지표 개발에 AHP 방법을 이용하였고, Joo et al. (2018)은 홍수 취약성 평가를 위한 지표개발에 있어, 기존 홍수취약성 분석에 이용된 다양한 인자들 중 취약성분석과 상관성이 높은 인자를 주성분분석과 요인분석을 통하여 선별하였고, 회귀분석을 통하여 설명력을 검증하였다. D. Kim et al. (2011) 은 Delphi 기법을 이용하여 수자원분야 취약성 분석을 위한 인자별 중요도를 결정하였다.

Song et al. (2013)은 PSR 구조체계를 이용하여 낙동강 유역의 시군구별 홍수위험지수를 개발하였는데, 각 지표의 가중치 산정을 Entropy 방법에 의하여 결정하였다. Yang and Kim (2013)는 선정된 지표를 Mann-Kendall trend test, Hotelling-Pabst trend test, Sen's trend test 등 3가지 경향성 검정을 통해 지표를 표준화하고, Delphi기법을 이용하여 지표별 가중치를 결정하여 낙동강 유역에 대한 가뭄 취약성 지수를 개발하였다. Lim et al. (2010)은 PRS 구조를 이용하여 전국 시군구별 홍수위험지수를 개발하였다.

자연재해에 대한 취약성분석은 홍수(T.H. Kim et al., 2011; Hong et al., 2015; Lee and Choi, 2016; Lim and Park, 2016)에 대한 연구가 대부분을 차지하며, 수자원(Won et al., 2014), 대설(Kwon et al., 2016), 도시재해(Kim and Choi, 2014), 지하수위 관리(Yang et al., 2017), 사회경제적 재해 (Park et al., 2016) 등 다양한 분야에 대하여 연구되었다.

본 연구에서는 자연재해 중 가장 큰 피해를 유발하는 태풍에 대한 위험지수를 개발하고자 한다. 태풍피해는 호우 로 인한 홍수, 강풍에 의한 피해, 태풍중심부의 저기압으로 인한 해수면 상승과 강풍으로 인한 풍랑 피해가 동시에 발생한다. 따라서 3 가지 재해형태를 고려할 수 있는 지표들 을 발굴하고, 이를 이용한 위험지수를 개발하고자 한다. 위험지수개발은 PSR 구조체계를, 지표별 가중치는 엔트로
피(Entropy) 방법을 이용하였다.

\section{2. 태풍위험지수산정 방법}

PSR 구조체계(Pressure-State-Response framework)는 인 과관계 접근방식의 평가체계로 전 세계적으로 널리 이용되 고 있는 방법으로(Lim et al., 2010), 각 지표의 특성이 명확하 며 재해의 원인, 결과, 예방의 유기적인 흐름의 지표수집이 가능한 장점(Song et al., 2013)이 있다. PSR 구조체계는 재해의 원인이 되는 압력지수(Pressure Index, PI), 재해로 인한 피해를 설명하는 현상지수(State Index, SI), 재해를 방어하거나 완화하기 위한 정책 또는 활동을 나타내는 대책 지수(Response Index, RI)로 구분되며, 이들 지표들을 이용하 여 다음과 같은 식으로 위험지수를 산정할 수 있다.

$$
T R I=P I^{\delta_{1}} \times S I^{\delta_{2}} \times R I^{\delta_{3}}
$$

여기서 $T R I$ 는 태풍위험지수(Typhoon Risk Index), PI, $S I, R I$ 는 각각 압력, 현상, 대책지수, $\delta_{1}, \delta_{2}, \delta_{3}$ 는 지수별 가중치로서 $\delta_{1}=\delta_{2}=\delta_{3}=1 / 3$ 로 균등한 가중치를 사용하였 다. 압력지수, 현상지수, 대책지수는 전술한 바와 같은 재해 의 원인, 피해, 방재를 위한 정책 또는 활동을 나타내는 각종 지표(Indicator)에 지표별 가중치를 곱하여 구할 수 있으며, 아래의 식과 같다.

$$
\begin{aligned}
& P I=\sum_{i=1}^{l} \alpha_{i} P F_{i} \\
& S I=\sum_{i=1}^{m} \beta_{i} S F_{i} \\
& R I=\sum_{i=1}^{l} \gamma_{i} R F_{i}
\end{aligned}
$$

여기서 $\mathrm{PF}, \mathrm{SF}, \mathrm{RF}$ 는 각각 압력지표(Pressure Indicators), 현상지표(State Indicators), 대책지표(Response Indicators) 를 나타내며, $\alpha_{i}, \beta_{i}, \gamma_{i}$ 는 i번째 압력지표, 현상지표, 대책지표 에 대한 가중치이며, 본 연구에서는 각 지표의 가중치를 Entropy 방법을 이용하여 산정하였다. Entropy 방법을 이용 한 가중치 산정방법은 사용자 주관이 배제되고, 이용된 지표 의 속성정보만을 이용하여 가중치를 산정하는 방법(Song et al., 2013)으로 알려져 있다.

\section{3. 태풍위험지수 산정}

\section{1 지표 선정}

자연재해 관련 각종 위험지수 또는 취약성분석을 위해 
선정되는 지표들은 각 재해에 영향을 줄 수 있는 인자들을 선정하고, 이를 개량화하여 위험지수 또는 취약성분석에 이용하게 된다(Yang et al., 2017). PSR 구조체계에서 압력요 인에 해당하는 지표는 재해를 유발하는 원인이 되는 지표로 홍수의 경우는 수문기상인자를 들 수 있고, 피해가 발생하는 대상이 되는 것으로 지역특성을 나타내는 인자가 대부분을 차지하며, 마지막으로 사회경제적 요인을 들 수 있다(T.H. Kim et al., 2011). 현상요인에 해당하는 지표는 재해로 직접 적인 피해를 당한 요인들 이며, 대책요인은 피해를 예방하기 위한 또는 피해를 줄이기 위한 다양한 노력을 나타내는 지표이다.

태풍재해는 호우로 인한 홍수피해, 강풍으로 인한 피해 및 연안지역의 경우 풍랑으로 인한 피해가 동시에 발생하므 로 이를 모두 만족할 수 있는 지표를 개발하는 것이 필요하다. PSR 구조체계에서 압력지수에 해당하는 지표는 재해의 원 인이 되는 수문기상인자, 지역특성인자, 사회경제적 인자로 구분하였다. 먼저 홍수재해와 관련된 인자로는 호우주의보 를 발령하는 기준이 되는 $30 \mathrm{~mm} / \mathrm{hr}$ 이상의 강우강도를 나타 낸 회수, 시간당 최대강우량 $(\mathrm{mm} / \mathrm{hr})$, 일최대강우량 $(\mathrm{mm})$ 등 강우와 관련된 지표를 산정하였다. 수문기상관측소에 관측 하여 발표하는 바람관련 자료는 평균풍속, 최대풍속, 최대순 간풍속이 있으며, 3 가지 관측치중 최대순간풍속이 강풍피해 와 가장 큰 상관관계를 나타내는 것으로 나타났으므로(Song and Yang, 2016), 본 연구에서 최대순간풍속을 채택하였다. 연안지역 피해의 많은 부분은 방조제, 항만, 어항, 양식을 위한 각종 어구, 어망 등이며, 이는 바람과 저기압으로 인한 해수면 상승으로 기인한 것이 많다. 따라서 연안피해를 태풍 위험지수에 고려하기 위하여서는 조위상승에 대한 영향을 고려하여야 하나, 만조와 간조 시 발생하는 조차가 동해안과 서해안이 다르게 나타나므로 조위상승을 지표화 하는데 어려움이 있어 지표항목에서 제외하였다.

최대순간풍속을 포함한 수문기상인자는 1994년부터 2016년까지 피해를 준 태풍 35개를 대상으로 하였다(Table 1). 실제 우리나라에 피해를 준 태풍은 이보다 많으나, 태풍 전후로 호우가 발생하여, 재해구분으로는 호우태풍으로 분 류되는 것은 제외하였다.

압력지수중 지역특성을 나타내는 지표로는 홍수위험지수 또는 취약성분석에 적용하는 도시화율, 건물노후도, 하천길 이, 도로길이를 선정하였으며, 하천과 도로 피해가 공공시설 물 피해 중 가장 크게 나타나기 때문이다. 사회경제적 지표로 는 인구밀도와 지역내 총생산(GRDP)을 선택하였다.

현상지표로는 태풍피해회수, 태풍피해액과 국립해양조사 원에서 개발한 연안재해영향지수(Coastal Potential Impact Index, CPII)를 선정하였고(KHOA, 2011), 대책요인으로는 하천개수율, 배수펌프장수, 재정자립도, 공무원 수, 방재예 산 등을 선정하였으며, Table 2에 나타나있다.

Table 1. Typhoon List (1994-2016)

\begin{tabular}{|c|c|c|c|c|c|c|c|c|c|}
\hline No. & Typhoon & $\begin{array}{c}\text { Affecting } \\
\text { start }\end{array}$ & $\begin{array}{c}\text { Affecting } \\
\text { end }\end{array}$ & $\begin{array}{c}\text { Pressure } \\
\text { at } 33^{\circ}\end{array}$ & No. & Typhoon & $\begin{array}{c}\text { Affecting } \\
\text { start }\end{array}$ & $\begin{array}{c}\text { Affecting } \\
\text { end }\end{array}$ & $\begin{array}{c}\text { Pressure } \\
\text { at } 33^{\circ}\end{array}$ \\
\hline 1 & BRENDAN & 1994-07-31 & 1994-08-02 & $984 \mathrm{hPa}$ & 19 & SHANSHAN & 2006-09-16 & 2006-09-18 & $970 \mathrm{hPa}$ \\
\hline 2 & DOUG & 1994-08-09 & 1994-08-12 & $978 \mathrm{hPa}$ & 20 & MAN-YI & $2007-07-13$ & $2007-07-16$ & $977 \mathrm{hPa}$ \\
\hline 3 & ELLIE & 1994-08-14 & 1994-08-16 & $972 \mathrm{hPa}$ & 21 & NARI & 2007-09-13 & 2007-09-18 & $963 \mathrm{hPa}$ \\
\hline 4 & SETH & 1994-10-10 & 1994-10-12 & $972 \mathrm{hPa}$ & 22 & KALMAEGI & 2008-07-19 & 2008-07-21 & $1007 \mathrm{hPa}$ \\
\hline 5 & FAYE & $1995-07-23$ & 1995-07-24 & $962 \mathrm{hPa}$ & 23 & DIANMU & 2010-08-09 & 2010-08-12 & $983 \mathrm{hPa}$ \\
\hline 6 & TINA & 1997-08-07 & 1997-08-09 & $982 \mathrm{hPa}$ & 24 & KOMPASU & 2010-09-01 & 2010-09-03 & $949 \mathrm{hPa}$ \\
\hline 7 & OLIWA & 1997-09-15 & 1997-09-17 & $972 \mathrm{hPa}$ & 25 & MALOU & 2010-09-05 & 2010-09-07 & $989 \mathrm{hPa}$ \\
\hline 8 & YANNI & 1998-09-29 & 1998-10-01 & $979 \mathrm{hPa}$ & 26 & MUIFA & 2011-08-06 & 2011-08-10 & $981 \mathrm{hPa}$ \\
\hline 9 & ANN & 1999-09-17 & 1999-09-24 & $993 \mathrm{hPa}$ & 27 & KAHNUN & 2012-07-17 & 2012-07-19 & $984 \mathrm{hPa}$ \\
\hline 10 & PRAPIROON & $2000-08-30$ & 2000-09-01 & $966 \mathrm{hPa}$ & 28 & BOLAVEN & 2012-08-25 & 2012-08-30 & $970 \mathrm{hPa}$ \\
\hline 11 & SAOMAI & 2000-09-12 & $2000-09-16$ & $972 \mathrm{hPa}$ & 29 & SANBA & 2012-09-14 & 2012-09-17 & $954 \mathrm{hPa}$ \\
\hline 12 & RAMMASUN & 2002-07-05 & 2002-07-06 & $986 \mathrm{hPa}$ & 30 & DANAS & 2013.10 .07 & 2013.10 .10 & $970 \mathrm{hPa}$ \\
\hline 13 & RUSA & 2002-08-30 & 2002-09-01 & $972 \mathrm{hPa}$ & 31 & NEOGURI & 2014.07 .08 & 2014.07 .10 & $996 \mathrm{hPa}$ \\
\hline 14 & SOUDELOR & 2003-06-18 & 2003-06-19 & $973 \mathrm{hPa}$ & 32 & NAKRI & 2014.08 .01 & 2014.08 .04 & $974 \mathrm{hPa}$ \\
\hline 15 & MAEMI & 2003-09-11 & 2003-09-13 & $940 \mathrm{hPa}$ & 33 & HALONE & 2014.08 .08 & 2014.08 .10 & $974 \mathrm{hPa}$ \\
\hline 16 & MEGI & 2004-08-17 & 2004-08-19 & $976 \mathrm{hPa}$ & 34 & GONI & 2015.08 .23 & 2015.08 .27 & $949 \mathrm{hPa}$ \\
\hline 17 & NABI & 2005-09-06 & 2005-09-08 & $962 \mathrm{hPa}$ & 35 & CHABA & 2016-10-03 & 2016-10-06 & 967hpa \\
\hline 18 & WUKONG & $2006-08-17$ & $2006-08-21$ & $995 \mathrm{hPa}$ & & & & & \\
\hline
\end{tabular}


Table 2. Indicators for Typhoon Damage Index

\begin{tabular}{|c|c|c|c|c|c|c|}
\hline & Type & Item & Ind. & Type & Item & Ind. \\
\hline \multirow{10}{*}{ Pressure } & \multirow{4}{*}{ hydro-meteorologic } & number over $30 \mathrm{~mm} / \mathrm{hr}$ & PF1 & \multirow{3}{*}{ State } & Coastal potential impact index & SF1 \\
\hline & & Max. hourly rainfall $(\mathrm{mm} / \mathrm{hr})$ & PF2 & & Number of typhoon damage & SF2 \\
\hline & & Max. hourly rainfall (mm/day) & PF3 & & Typhoon damage cost & SF3 \\
\hline & & $\begin{array}{l}\text { Max. instantaneous Wind Velocity } \\
(\mathrm{m} / \mathrm{sec})\end{array}$ & PF4 & \multirow{6}{*}{ Response } & Embankment improvement & RF1 \\
\hline & \multirow{4}{*}{ regional } & Urbanization (\%) & PF5 & & $\begin{array}{l}\text { Number of public servants per } \\
\text { resident }\end{array}$ & RF2 \\
\hline & & Building aging & PF6 & & Pump station number & $\mathrm{RF} 3$ \\
\hline & & Stream length $(\mathrm{km})$ & PF7 & & Pump station capacity $\left(\mathrm{m}^{3} / \mathrm{hr}\right)$ & RF4 \\
\hline & & Road length (km) & PF8 & & Financial independence rate & RF5 \\
\hline & \multirow{2}{*}{ socio-economic } & Population density (person $/ \mathrm{km}^{2}$ ) & PF9 & & Ddisaster prevention budget & RF6 \\
\hline & & GRDP & PF10 & & & \\
\hline
\end{tabular}

\section{2 엔트로피(Entropy) 방법에 의한 가중치 산정}

각 지표의 가중치를 산정하는 방법으로 엔트로피방법을 이용하였다. 연구자의 주관적 개입을 배제하고, 지표에 의해 주어지는 정보만을 이용하는 방법으로 적용절차는 Fig. 1과 같다(Choi et al., 2013). Table 2에 나타나 있는 태풍위험지수 를 산정하기 위한 지표 중 $30 \mathrm{~mm} / \mathrm{hr}$ 회수, 태풍피해회수는 피해가 발생하지 않은 지역의 경우에는 ' 0 '의 값을 가지며, $\log (0)$ 를 계산할 수 없으므로, 대단히 작은 값 $\left(10^{-9}\right)$ 으로 대치 하여 엔트로피 가중치를 산정하였으며, 그 결과가 Table 3 에 나타나 있다. 본 연구에서는 각각의 지수별로 가중치 $\left(w_{j}\right)$ 합이 ' 1 '이 되도록 산정하였다.

압력지수를 대표하는 10 개 지표 중 최대순간풍속, 도시화 율, 건물노후도는 상대적으로 작은 가중치를 나타내며, 30 $\mathrm{mm} / \mathrm{hr}$ 이상 회수, 인구밀도가 높은 가중치를 나타내었다. 3 개의 상태지표 중 피해회수의 가중치가 작으며, 연안재해 영향지수와 피해액은 거의 같은 크기의 가중치를 가지는 것으로 계산되었다. 대책지수는 하천개수율과 재정자립도
가 낮은 가중치를 나타내었다.

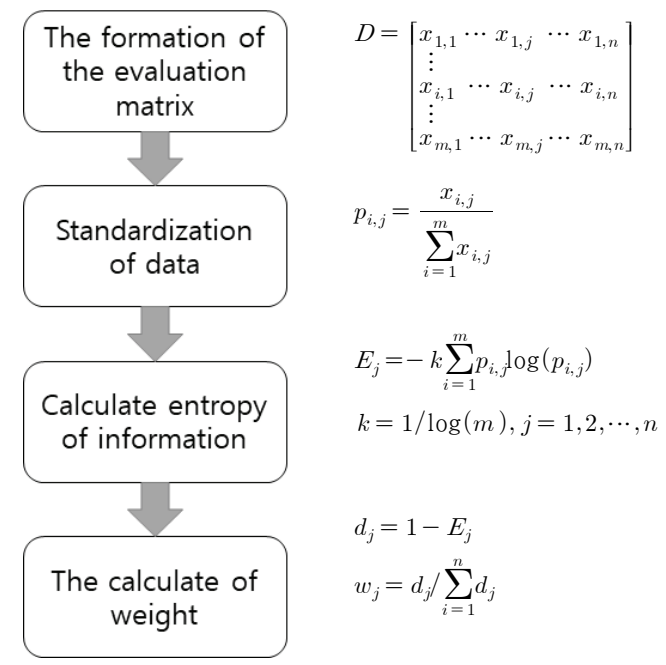

Fig. 1. Entropy Weight Calculation Process (Choi et al., 2013)

Table 3. Weights of Indicators by Entropy Method

\begin{tabular}{|c|c|c|c|c|c|c|c|c|c|c|}
\hline \multirow{2}{*}{ Items } & \multicolumn{10}{|c|}{ Pressure Index } \\
\hline & PF1 & PF2 & PF3 & PF4 & PF5 & PF6 & PF7 & PF8 & PF9 & PF10 \\
\hline$\sum p_{i j} \log \left(p_{i j}\right)$ & -1.967 & -2.286 & -2.293 & -2.340 & -2.336 & -2.342 & -2.134 & -2.108 & -1.914 & -2.124 \\
\hline$E_{j}$ & 0.840 & 0.976 & 0.979 & 0.999 & 0.997 & 1.000 & 0.911 & 0.900 & 0.817 & 0.907 \\
\hline$d_{j}$ & 0.160 & 0.024 & 0.021 & 0.001 & 0.003 & 0.000 & 0.089 & 0.100 & 0.183 & 0.093 \\
\hline$w_{j}$ & 0.238 & 0.036 & 0.031 & 0.001 & 0.004 & 0.000 & 0.132 & 0.149 & 0.271 & 0.138 \\
\hline \multirow{2}{*}{ Items } & \multicolumn{3}{|c|}{ State Index } & \multicolumn{6}{|c|}{ Response Index } & \\
\hline & SF1 & SF2 & SF3 & RF1 & RF2 & RF3 & RF4 & RF5 & RF6 & \\
\hline$\sum p_{i j} \log \left(p_{i j}\right)$ & -1.836 & -2.270 & -1.829 & -2.173 & -1.939 & -1.990 & -1.725 & -2.309 & -1.844 & \\
\hline$E_{j}$ & 0.784 & 0.969 & 0.781 & 0.928 & 0.828 & 0.850 & 0.736 & 0.986 & 0.787 & \\
\hline$d_{j}$ & 0.216 & 0.031 & 0.219 & 0.072 & 0.172 & 0.150 & 0.264 & 0.014 & 0.213 & \\
\hline$w_{j}$ & 0.464 & 0.066 & 0.470 & 0.082 & 0.195 & 0.170 & 0.298 & 0.016 & 0.240 & \\
\hline
\end{tabular}




\section{3 태풍위험지수 산정}

태풍위험과 관련된 압력지수에 해당하는 10 개 지표, 현상 지수 3 개 지표, 대책지수 6 지표에 대한 가중치를 산정하였고, 이를 근거로 Eq. (2)를 이용하여 압력, 현상, 대책지수에 대한 값을 산정하였고, Eq. (1)을 이용하여 태풍위험지수 (TRI)를 산정하였으며, 그 결과가 Table 4와 Fig. 2에 나타나 있으며, 지수별 상-하위 10 개 시군구만 나타나 있다.

\section{4. 홍수위험도 분석}

\section{1 태풍위험지수에 이용된 지표별 분석}

Fig. 3에는 시군구별 지표별 크기가 나타나 있다. 압력지수 (PI)는 태풍피행의 원인이 되는 수문기상지표와 지역적 특성 및 사회• 경제적지표로 구분되는데, 수문기상지표인 $30 \mathrm{~mm}$ 이상 호우발생 회수, 1 시간 최대강우량 및 일최대강우량

Table 4. Order of PSR Index

\begin{tabular}{|c|c|c|c|c|}
\hline order & PI & SI & RI & TRI \\
\hline 1 & Seoul Gangnam-gu & Gangwon Gangneung city & Incheon Bupyeong-gu & Gyeongnam Changwon city \\
\hline 2 & Seoul Songpa-gu & Gangwon Samcheok city & Gangwon Pyongchang-gu & Gyeongnam Sacheon city \\
\hline 3 & Seoul Yangcheon-gu & Gangwon Yangyang-gun & Gangwon Inje-gun & Gangwon Gangneung city \\
\hline 4 & Seoul Dongdaemun-gu & Gyeongnam Changwon city & Gangwon Jeongseon-gun & Gangwon Jeongseon-gun \\
\hline 5 & Seoul Yeongdeungpo-gu & Gyeongbuk Gimcheon city & Gyeongnam Sacheon city & Gangwon Yangyang-gun \\
\hline 6 & Seoul Seocho-gu & Jeonnam Yeosu city & Chungnam Buyeo-gum & Gyeongnam Hadong-gun \\
\hline 7 & Seoul Dongjak-gu & Gangwon Goseong-gun & Gyeongnam Gimhae city & Jeonnam Gwangyang city \\
\hline 8 & Seoul Gwangjin-gu & Gyeongnam Tongyeong city & Gyeonggi Paju city & Busan Jung-gu \\
\hline 9 & Seoul Gangdong-gu & Gyeongnam Geoje city & Gyeongnam Uiryeong-gun & Gyeongnam Gimhae city \\
\hline 10 & Seoul Guro-gu & Gyeongnam Namhae-gun & Gyeongnam Jinju city & Gyeongnam Jinju city \\
\hline$\vdots$ & $\vdots$ & $\vdots$ & $\vdots$ & $\vdots$ \\
\hline 220 & Gyeongbuk Yecheon-gun & Seoul Yeongdeungpo-gu & Daejeon Dong-gu & Daejeon Jung-gu \\
\hline 221 & Gangwon Yanggu-gun & Seoul Mapo-gu & Jeonnam Damyang-gun & Gyeonggi Gwacheon city \\
\hline 222 & Chungbuk Boeun-gun & Chungnam Gyeryong city & Incheon Ganghw-gun & Chungbuk Jeungpyeong-gun \\
\hline 223 & Gyeonggi Gwacheon city & Seoul Guro-gu & Gyeongbuk Yeongyang-gun & Chungnam Gyeryong city \\
\hline 224 & Gyeongbuk Gunwi-gun & Seoul Dongdaemun-gu & Jeonbuk Sunchang-gun & Seoul Dongdaemun-gu \\
\hline 225 & Gyeonggi Dongducheon cit & Seoul Dongjak-gu & Gyeongbuk Gunwi-gun & Seoul Seongdong-gu \\
\hline 226 & Chungnam Taean-gun & Seoul Jung-gu & Incheon Jung-gu & Seoul Jung-gu \\
\hline 227 & Chungnam Gyeryong city & Seoul Jungnang-gu & Gangwon Taebaek city & Seoul Jungnang-gu \\
\hline 228 & Chungbuk Jeungpyeong-gun & Seoul Seongdong-gu & Jeonnam Sinan-gun & Seoul Dongjak-gu \\
\hline 229 & Incheon Ongjin-gun & Seoul Dobong-gu & Incheon Ongjin-gun & Seoul Dobong-gu \\
\hline
\end{tabular}

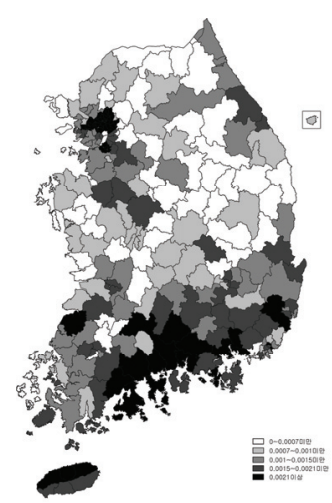

(a) Pressure Index

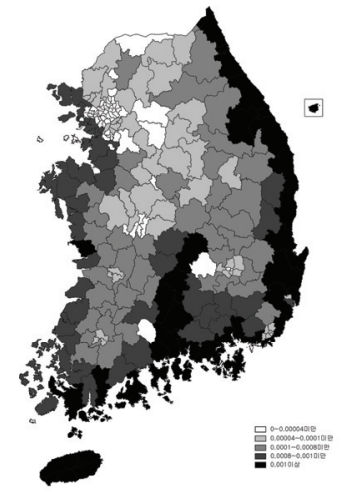

(b) State Index

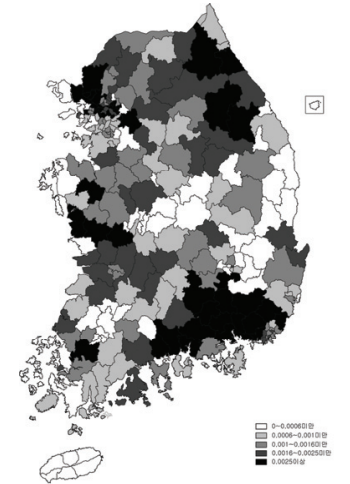

(c) Response Index

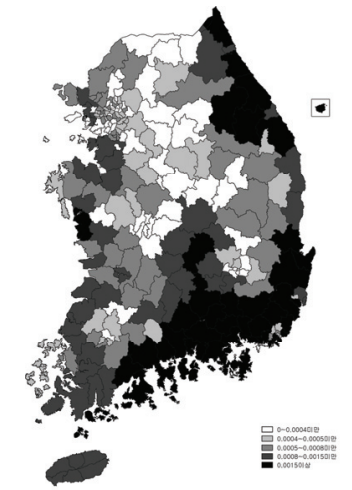

(d) Typhoon Damage Index

Fig. 2. Map of Typhoon Risk Index 


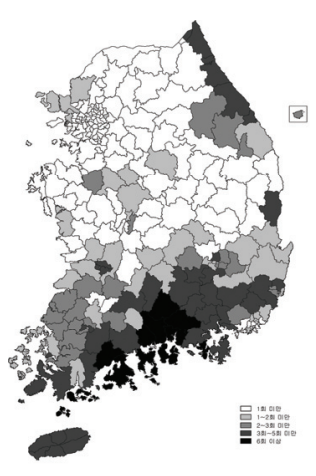

(a) Number over $30 \mathrm{~mm} / \mathrm{hr}$

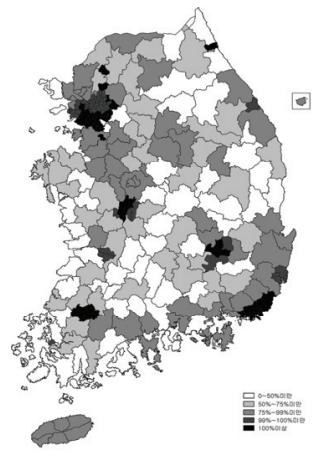

(e) Urbanization

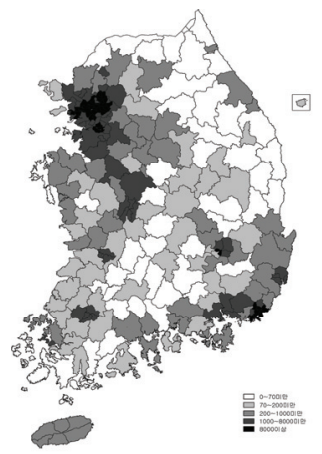

(i) Population density

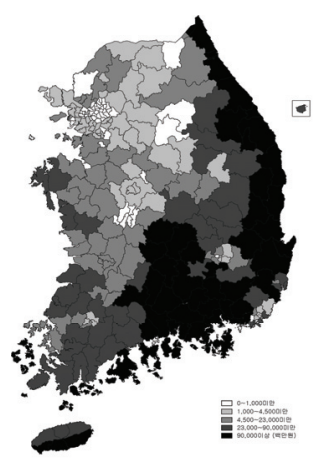

(m) Typhoon damage cost

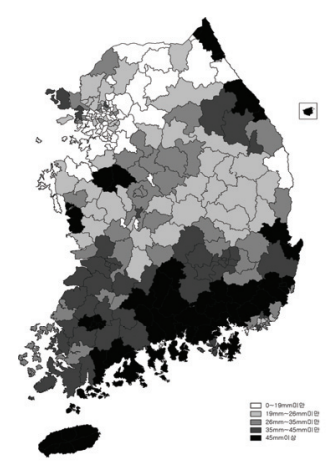

(b) Max. hourly rainfall $(\mathrm{mm} / \mathrm{hr})$

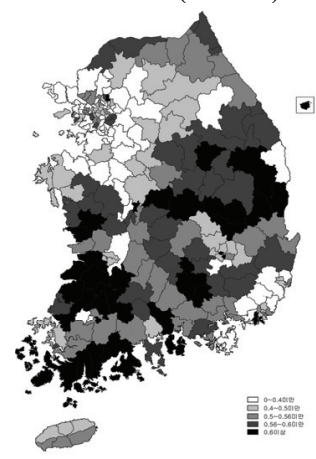

(f) Building aging

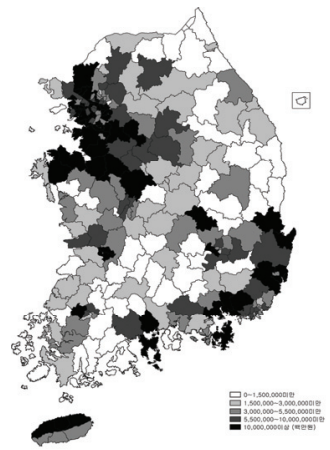

(j) GRDP

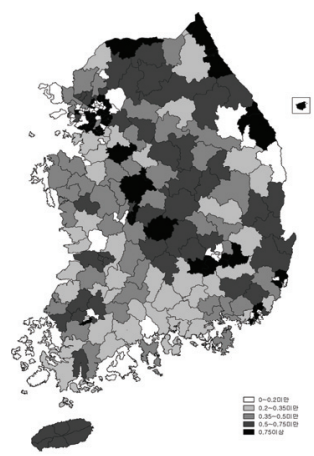

(n) Embankment improvement

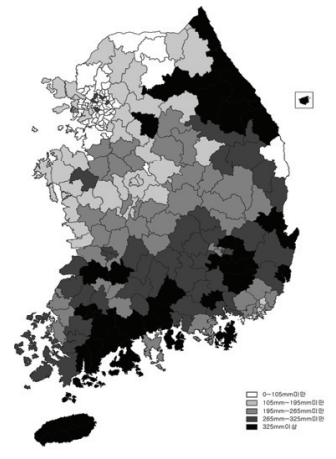

(c) Max. hourly rainfall

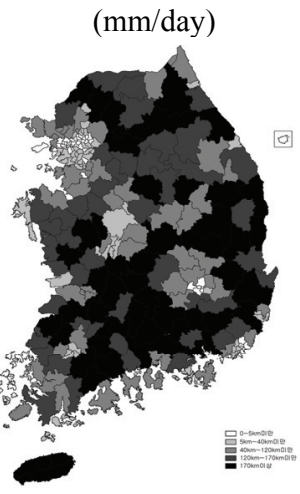

(g) Stream length

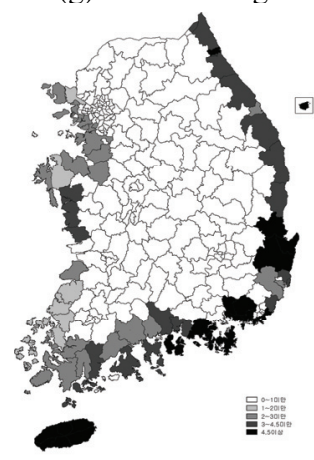

(k) Coastal potential impact index

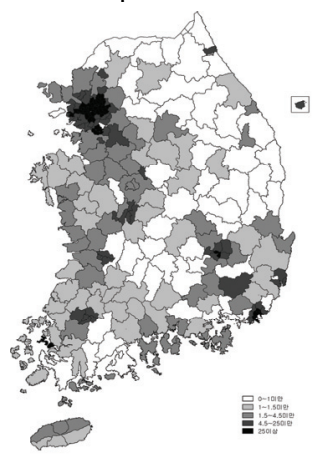

(o) Number of public servants per resident

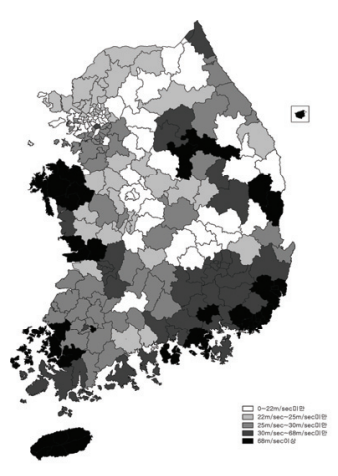

(d) Max. instantaneous Wind Velocity

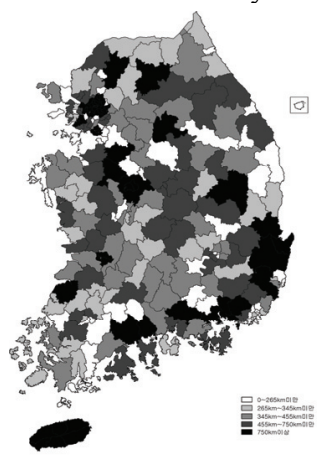

(h) Road length

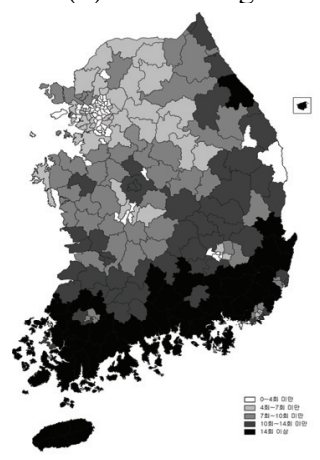

(1) Number of typhoon

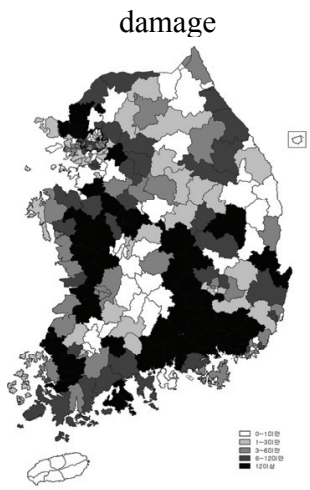

(p) Pump station number

Fig. 3. Map of Indicators for Typhoon Damage Index 


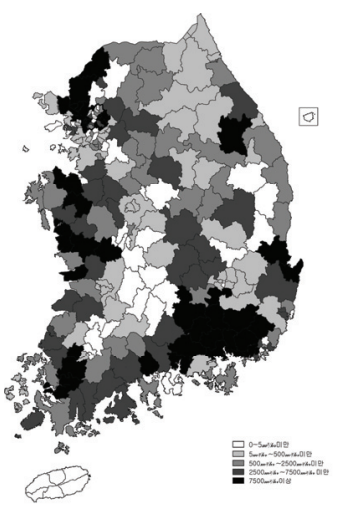

(q) Pump station capacity $\left(\mathrm{m}^{3} / \mathrm{hr}\right)$

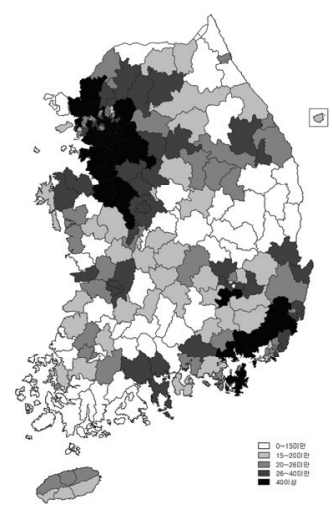

(r) Financial independence rate

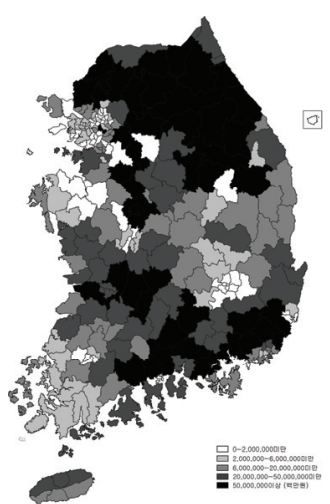

(s) Ddisaster prevention budget

Fig. 3. Map of Indicators for Typhoon Damage Index (continued)

등 호우와 관련된 지표들이 남해안과 강원도 및 경남북의 백두대간 동쪽지역이 크게 나타나는 것을 알 수 있다. 한반도 의 남쪽에 위치한 전라남도, 경상남도 부산, 울산 등의 지역 은 태풍의 세력이 유지된 상태로 영향을 미치기 때문이고, 백두대간 동쪽에 위치한 시군구는 회전하며 진행하는 태풍 의 오른 쪽에 위치하는 경우가 많고, 회전하는 태풍과 백두대 간에 의한 산악효과에 따른 결과로 보여진다. 강풍에 의한 피해를 유발하는 최대순간풍속은 남부지역이 크게 나타나 기는 하나, 경북일부지역과 충남 해안지방도 크게 나타나는 것을 알 수 있다. 한편 지형특성 및 사회 - 경제적 특성을 나타내는 지표는 건물노후도와 하천연장을 제외하고는 대 부분이 도시지역의 지표가 높게 나타난다.

상태지수 $(\mathrm{SI})$ 를 산정하기 위한 지표 중 연안재해영향지수 는 동해안과 경상남도에 위치한 시군구가 전라남도 및 서해 안에 위치한 시군구보다 크게 나타남을 알 수 있고, 태풍피해 회수와 태풍피해액은 거의 동일하게 나타난다. 연안재해영 향지수와 태풍피해액의 엔트로피 가중치가 $0.464,0.470$ 으 로 대부분을 차지하므로, 두 요소에 크게 좌우된다.

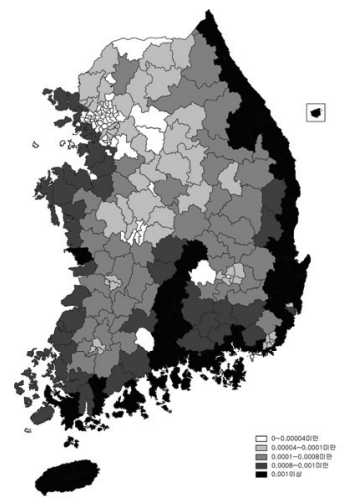

(a) State Index with CPII
연안재해영향지수는 연안지역에만 해당되므로 내륙지역 의 상태지수는 연안지역에 비하여 상대적으로 낮게 나타난 다. 연안위험지수의 가중치가 유발할 수 있는 상태지수의 왜곡여부를 판단하기 위하여 지표에서 연안위험지수를 제 거하고 상태지수를 산정하여 비교하였다. 즉 피해회수와 피해액만을 지표로 선택하여 엔트로피 가중치를 산정하고 상태지수를 산정하였으며, 그 결과가 Fig. 4에 나타나 있다. Fig. 4 를 살펴보면, 연안재해영향지수의 포함 여부에 따라 동해안과 남해안의 연안지역 상태지수는 비슷한 분포를 보이 지만, 서해안지역의 시군구는 연안재해영향지수를 지표로 고려하지 않는 경우에는 지수가 작아진다. 서해안 지역에 피해를 유발하기 위하여서는 태풍의 진로가 서해안을 따라 북상하여야 하나, 많은 태풍은 남해안으로 상륙하여 동해안으 로 빠져나가므로, 태풍진로의 왼쪽 반원에 위치하여 상대적으 로 피해가 작다. 내륙지방의 변화는 덕유산에 인접한 충청북 도, 전라북도 시군구의 상태지구가 높게 나타나는 것을 알 수 있다.

대책지수(RI)는 6개 지표로 이루어지는데 공무원밀도와

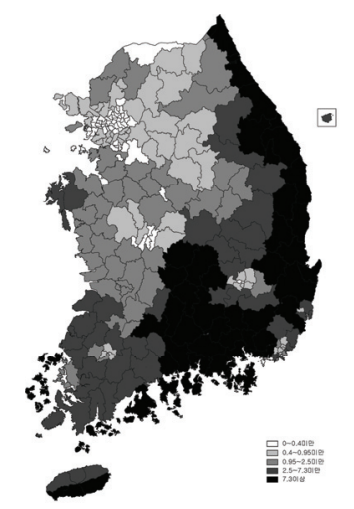

(b) State Index without CPII

Fig. 4. Comparision of SI 
재정자립도는 수도권지역과 부산, 대구, 울산 등 대도시 중심 으로 높은 값을 나타내었으며, 펌프장 수, 펌프용량 및 방재예 산 지표는 3 지표간의 상관성을 찾기 어렵다. 방재예산의 경우는 강원도 경기북부 등 태풍피해가 크게 발생하지 않는 지역이 높게 나타나는 것은 호우에 의한 피해(홍수피해)가 빈발하는 지역에 방재예산을 투자한 것으로 판단할 수 있다.

\section{2 태풍위험지수}

10 가지 지표에 의해 산정되는 압력지수(PI)는 서울시를 포함한 수도권 일부 시군구와 전남, 경남 등 남부지역에 속한 시군구가 크게 나타난다. 서울시를 포함한 수도권 일부 시군구의 압력지수가 높은 것은 지형특성 및 사회 - 경제적 지표 중 도로길이, 인구밀도, $\mathrm{GRDP}$ 의 엔트로피 가중치가 $0.05,0.09,0.046$ 으로 3 지표의 가중치 합이 0.558 로서 압력지 수의 절반 이상을 차지하기 때문으로 분석된다. 남부지역에 속한 시군구의 압력지수가 높은 것은 강우와 관련된 수문기 상학적 충격이 크기 때문이다.

현상지수(SI)는 앞에서 언급한 바와 같이 연안재해영향지 수와 태풍피해액이 높은 가중치를 가지므로 동해안 전 지역 과 경남, 전남의 남해안 지역 및 지리산을 중심으로 한 서부 경남지역(산청군, 함양군, 하동군 등)이 크게 나타남을 알 수 있으며, 지리산 주변 시군구 역시 영동지역과 마찬가지로 지리산에 의한 산악효과에 의한 것으로 판단된다.

대책지수는 시군구의 재정적 상황과 관련된 지표(공무원 수, 재정자립도)는 수도권이 높게 나타났고, 나머지 지표는 특별한 경향성을 파악하기 어렵다. 또 Table 3의 엔트로피 가중치를 살펴보면 지역적인 또는 피해와 관련된 경향을 발견할 수 없는 펌프용량과 방재예산의 가중치가 0.278 과 0.240 을 차지하므로, 대책지수 또한 특별한 경향성을 찾을 수는 없으나 재정자립도가 높은 수도권 일부지역과 경상남 도 지역이 비교적 높게 나타난다.

태풍위험지수는 Eq. (2)에 따라 산정한 태풍위험지수 (TRI)는 태풍피해가 많이 발생하는 것으로 알려진 남해안 지역과 백두대간의 동쪽에 위치한 시군구 및 덕유산과 지리 산 인접 시군구의 태풍위험지수가 높게 나타남을 알 수 있으며, 이는 태풍피해회수, 태풍피해액과 비슷한 결과를 보인다. 연안지역 중 서해안에 위치한 시군구의 태풍위험지 수가 동해안 및 남해안에 비하여 낮게 나타나는 것은 태풍의 진로가 서해안을 따라 통과하는 경우가 상대적으로 작아 태풍피해회수 및 피해액이 작기 때문으로 판단된다. 전북, 경북내륙지역 및 중부내륙지역의 대부분의 시군구는 태풍 피해로부터 비교적 안전함을 알 수 있다.

\section{5. 결 론}

우리나라에서 발생하는 자연재해 중 큰 비중을 차지하는 태풍피해에 대한 대비를 위하여 태풍피해 가능성이 높은
지역과 낮은 지역을 구분하고, 방재 관련 사업의 투자 우선순 위를 결정하는 데 도움이 될 수 있는 태풍위험지수(Typhoon Risk Index, TRI)를 229개 시군구에 대하여 산정하였다. 태풍위험지수 산정방법은 PSR 구조체계를 이용하였으 며, 지수를 구성하는 지표의 가중치는 엔트로피 방법을 이용 하여 산정하였다. 압력지수 $(\mathrm{PI})$ 는 태풍내습 시 발생한 수문 기상 지표와 태풍발생시 피해빈도가 높은 하천, 도로 등 지역적 특성 지표 및 사회• 경제적 지표 등 10 개의 지표로 이루어지며, 상태지수는 태풍피해와 관련된 3 개의 지표로 이루어진다. 대책지수는 태풍내습시 발생하는 피해에 대한 대처능력 또는 예방 능력을 나타내는 지표로 지장자치단체 의 재정적 능력, 방재시설과 관련된 지표로 이루어져 있다.

산정된 압력지수는 태풍이 자주 내습하는 남해안 지역과 인구와 도로가 많은 서울시에 위치한 시군구가 높게 나타났 고, 태풍피해가 적은 중부내륙 지역 및 충남 서해안의 압력 지수는 남해안 및 동해안의 연안지역에 비하여 상대적으로 낮게 나타났다. 태풍으로 인한 피해를 알아볼 수 있는 상태 지수는 태풍이 세력을 유지한 채 피해를 야기하는 남해안 지역의 시군구와 백두대간, 지리산, 덕유산과 같은 높은 산과 회전하는 태풍에 의한 산악효과로 많은 비가 내리는 지역이 높게 나타났으며, 중부내륙지역과 서울을 포함한 수도권은 비교적 낮게 나타났음을 알 수 있다. 대책지수는 자연재해와 관련된 각종 사업과 지방자치단체의 재정능력 에 따라 결정되는데 일정한 경향성을 찾기 어려웠으나, 재해가 자주 발생하는 경남, 경기 서북부 및 강원 북부가 높게 나타났다. 마지막으로 PSR 구조체계에 의해 산정된 태풍피해지수는 남해안 및 동해안 지역과 지리산 및 덕유 산 인근에 위치한 시군구가 높게 나타났으며, 중부내륙지 역이 낮게 나타났으며, 상태지수와 거의 동일한 형태를 보인다.

따라서 본 연구에서 산정한 태풍위험지수는 기왕에 발생 한 피해지역과 피해액을 잘 반영하는 것으로 판단되며, 이를 이용하여 태풍피해를 줄이기 위한 방재관련 사업의 우선 순위를 산정하거나, 태풍내습 시 대비를 위한 기초자료로 이용할 수 있을 것으로 판단된다.

한편, PSR 구조체계에 이용되는 지표선정에 대한 객관적 인 선정기준이 필요할 것으로 판단된다. Joo et al. (2018)은 기존에 개발된 다양한 홍수위험지수에 이용된 지표들 중 가장 대표성이 높을 것을 선정하여 새로운 홍수위험지수를 개발하였는데, 이와 같은 시도가 태풍위험과 관련하여 이루 질 필요가 있고, 상태지수의 경우는 피해이력과 관련된 항 이외에 다른 항목을 도입할 필요가 있다.

\section{감사의 글}

본 연구는 행정안전부 재난예측및저감연구개발사업의 지원을 받아 수행된 연구임(MOIS-재난-2015-05). 


\section{References}

Chae, B.G., Cho, Y.C., Song, Y.S., and Seo, Y.S. (2009). Development of an evaluation chart for landslide susceptibility using the AHP analysis method. The Journal of Engineering Geology, Vol. 19, No. 1, pp. 99-108.

Choi, H.I., Park, S.Y., Song, J.H., and Park, M.J. (2013). Identification of flood risk areas using a multi-criteria decision making method. J. Korean Soc. Hazard Mitig., Vol. 13, No. 2, pp. 237-243.

Hong, J., Lim, H.J., Ham, Y.H., and Lee, B.J. (2015). Grid unit based analysis of climate change driven disaster vulnerability in urban area. Journal of Korea Spatial Information Society, Vol. 23, No. 6, pp. 67-75.

Joo, H., Lee, M., Choi, C., Kim, S., and Kim, H.S. (2018). A study on the selection of representative indicators of flood vulnerability assessment. J. Korean Soc. Hazard Mitig., Vol. 18, No. 6, pp. 335 346.

Korea Hydrographic and Oceanographic Agency (KHOA). (2011). Coastal disaster assessment system. Retrieved from http://www.khoa.go.kr/cdas/cdasweb/

Kim, D., Jung, Y., Park, M.J., Yoon, J.Y., Kim, S., and Choi, M. (2011). Vulnerability analysis of water resources considering climate change. Journal of Wetlands Research, Vol. 13, No. 1, pp. 25-33.

Kim, J.H., and Kim, Y.O. (2003). Improving potential flood damage. Proceedings 2003 Annual Conference, Korean SCE, pp. 2373-2378.

Kim, J.W., and Choi, C.I. (2014). The development of methodology for urban disaster vulnerability and its implication. Journal of the Korean Regional Development Association, Vol. 26, No. 2, pp. 1-22.

Kim, T.H., Han, K.Y., and Cho, W.H. (2011). Vulnerability analysis in the Nakdong River basin for the utilization of flood risk mapping. Journal of the Korean Association of Geographic Information Studies, Vol. 14, No. 3, pp. 203-222.

Korea Research Institute for Human Settlements (KRIHS). (2005). Analysis of flood damage characteristics and development of flood damage index.

Kwon, S., Park, H., and Chung, G. (2016). Analysis of snow vulnerability and adaptation policy for heavy snow. J. Korean Soc. Hazard Mitig., Vol. 16, No. 2, pp. 363-368.

Lee, J.S., and Choi, H.I. (2016). Flood vulnerability assessment by analysis of flood damage data in coastal areas. J. Korean Soc. Hazard Mitig., Vol. 16, No.
2, pp. 377-385.

Lim, C.H., and Park, Y.Y. (2016). Study of a flood vulnerability assessment for climate change and utilizing the vulnerability-based disaster response in Jeju-do. Fire Science and Engineering, Vol. 30, No. 6, pp. 64-70.

Lim, K.S., Choi, S.J., Lee, D.R., and Moon, J.W. (2010). Development of flood risk index using relationships of flood indicators. Journal of the Korean Society of Civil Engineering, Vol. 30, No. 1B, pp. 61-70.

Ministry of Construction \& Transportation (MOCT). (2001). Water vision 2020.

Ministry of the Interior and Safety (MOIS). (2017). 2016 Disaster report.

Park, Y., Yang, J.S., and Kim, S. (2016). Social and economic disaster vulnerability assessment considering urban characteristics of Seoul. J. Korean Soc. Hazard Mitig., Vol. 16, No. 1, pp. 337-345.

Song, C.Y., and Yang, B.S. (2016). Gale disaster damage investigation process provement plan according to correlation analysis between wind speed and damage cost. Journal of the Korean Society of Safety, Vol. 31, No. 2, pp. 119-126.

Song, J.H., Kim, S., Park, M.J., and Choi, H.I. (2013). Estimation of flood risk index for the Nakdong River watershed. Journal of Korea Water Resources Association, Vol. 46, No. 1, pp. 35-45.

Won, K.J., Chung, E.S., Kim, Y.J., and Hong, I.P. (2014). Assessment of water resources vulnerability index by nation. J. Korea Water Resources Association, Vol. 47, No. 2, pp. 183-194.

Yang, J.S., and Kim, I.H. (2013). Development of drought vulnerability index using delphi method considering climate change and trend analysis in Nakdong River basin. Journal of the Korean Society of Civil Engineers, Vol. 33, No. 6, pp. 2245-2254.

Yang, J.S., Lee, J.B., and Kim, I.H. (2017). Assessment of the vulnerability of groundwater level management in Nakdong River basin. J. Korea Water Resour. Assoc., Vol. 50, No. 12, pp. 815-825. 